\title{
Anxiety and depression symptoms in Brazilian sexual minority ecstasy and LSD users
}

\author{
Sintomas de ansiedade e depressão em brasileiros não heterossexuais usuários \\ de ecstasy e LSD
}

Lysa S. Remy, ${ }^{1}$ Juliana Scherer, ${ }^{1}$ Luciano Guimarães,${ }^{1}$ Hilary L. Surratt, ${ }^{2}$ Steven P. Kurtz, ${ }^{3}$ Flavio Pechansky, ${ }^{1}$ Felix Kessler ${ }^{1}$

\begin{abstract}
Background: This study examined drug use patterns and psychiatric symptoms of anxiety and depression among young Brazilian sexual minority ecstasy and LSD users and compared findings with those reported for their heterosexual peers.

Method: This cross-sectional study employed targeted sampling and ethnographic mapping approaches via face-to-face interviews conducted at bars and electronic music festivals using an adapted, semi-structured version of the Global Appraisal of Individual Needs questionnaire. The sample comprised 240 male and female young adults who had used ecstasy and/or LSD in the 90 days prior to the interview and who were not on treatment for alcohol and drug abuse.

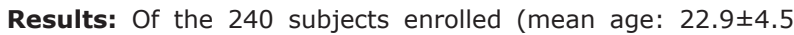
years), $28.7 \%$ were gay or bisexuals. Multivariate regression analysis showed that the prevalence of depression symptoms in the past 12 months in the sexual minority group was $37 \%$ higher than among heterosexuals (prevalence ratio $[\mathrm{PR}]=1.79 ; 95 \%$ confidence interval [95\%CI] 1.03-3.11; $\mathrm{p}=0.037$ ).

Conclusion: Strategies should be developed to assess and address individual needs and treatment approaches should be tailored to address depressive symptoms in young, sexual minority club drug users.
\end{abstract}

Keywords: Anxiety, depression, psychiatric symptoms, sexual minority, synthetic drugs.

\section{Resumo}

Introdução: Este estudo examinou os padrões de uso de drogas e os sintomas psiquiátricos de ansiedade e depressão entre brasileiros não heterossexuais usuários de ecstasy e/ou LSD e comparou os achados com aqueles relatados por seus pares heterossexuais.

Método: Este estudo transversal empregou amostragens direcionadas e abordagens de mapeamento etnográfico através de entrevistas presenciais realizadas em bares e festivais de música eletrônica usando uma versão adaptada e semiestruturada do questionário de Avaliação Global de Necessidades Individuais. A amostra incluiu 240 adultos jovens do sexo masculino e feminino que haviam usado ecstasy e/ou LSD nos 90 dias anteriores à entrevista e que não estavam em tratamento para abuso de álcool e drogas.

Resultados: Dos 240 sujeitos incluídos (idade média: 22,9 94,5 anos), $28,7 \%$ eram homossexuais ou bissexuais. A análise de regressão multivariada mostrou que a prevalência de sintomas de depressão nos últimos 12 meses no grupo não heterossexual foi $37 \%$ superior à dos heterossexuais [razão de prevalência $(\mathrm{RP})=1,79$; intervalo de confiança de $95 \%$ (IC95\%) 1.03-3.11; $\mathrm{p}=0,037]$.

Conclusão: Estratégias devem ser desenvolvidas para avaliar e abordar as necessidades individuais, e as abordagens de tratamento devem ser adaptadas para sintomas depressivos em usuários de drogas jovens e não heterossexuais.

Descritores: Ansiedade, depressão, sintomas psiquiátricos, não heterossexuais, drogas sintéticas.

\footnotetext{
${ }^{1}$ Centro de Pesquisa em Álcool e Droga, Hospital de Clínicas de Porto Alegre (HCPA), Universidade Federal do Rio Grande do Sul (UFRGS), Porto Alegre, RS, Brazil. ${ }^{2}$ University of Kentucky, Lexington, KY, USA. ${ }^{3}$ Nova Southeastern University, Miami, FL, USA.

Submitted Mar 09 2016, accepted for publication May 212017.

Suggested citation: Remy LS, Scherer J, Guimarães L, Surratt HL, Kurtz SP, Pechansky F, Kessler F. Anxiety and depression symptoms in Brazilian sexual minority ecstasy and LSD users. Trends Psychiatry Psychother. 2017;39(4):239-246. http://dx.doi.org/10.1590/2237-6089-2016-0081
} 


\section{Introduction}

Some studies suggest that young sexual minority individuals disproportionately experience mental health problems, particularly diagnoses of depression and anxiety, ${ }^{1}$ including suicidal thoughts and behaviors, selfmutilation, and addiction, as well as other psychiatric conditions, when compared with heterosexual individuals. ${ }^{2}$ Lifestyle, emotional and behavioral factors (including feelings of discrimination), excessive tobacco and other drug use, body image concerns, and extreme sexual promiscuity, among other aspects, may act as important factors ${ }^{3}$ to increase the risk of mental health disorders as well as substance abuse and sexually transmitted infections, including HIV. ${ }^{3-7}$ Mood disorders co-occurring with substance use and other risk behaviors increase social and occupational impairments, as well documented in several studies conducted, particularly in the USA and Europe. ${ }^{8}$

A representative study performed in England by Chakraborty et al. with a sexual minority population identified higher levels of neurotic disorder (odds ratio $[O R]=1.47)$, depressive episodes $(O R=1.80)$, obsessive compulsive disorder $(\mathrm{OR}=2.24)$, alcohol $(\mathrm{OR}=2.05)$ and drug dependence $(O R=1.70)$, as well as a higher prevalence of consultations with psychiatrists $(O R=1.46)$ when compared with the heterosexual group. ${ }^{9}$ Another study investigating the prevalence of mental disorders and substance abuse revealed that non-heterosexuals had twice the risk of suicide attempts compared to heterosexual individuals, and showed a prevalence of depression and anxiety disorders 1.5 times higher than the general population. ${ }^{10} \mathrm{~A}$ systematic review ${ }^{6}$ found that, in addition to having an increased risk of depression and anxiety disorders and suicide attempts, non-heterosexuals had a higher risk of drug addiction (relative risk range: 1.51 to 4.00 ) than the general population. ${ }^{11}$

Although a number of studies have found correlations between sexual minority, drug use and psychiatric symptoms, few have included developing country sexual minorities that are also synthetic drug users. ${ }^{12}$ Information about the mental health of non-heterosexual individuals, particularly in developing countries such as Brazil, is still inconclusive, whether due to the difficulties recruiting samples or the unwillingness of people to be open about their sexual orientation. The majority of studies have been conducted in the USA, ${ }^{12-15}$ Europe, ${ }^{16,17}$ and Australia. ${ }^{18}$ Approaches to sexual minority groups are pretty diverse across countries, once prejudice and social stigma are driven by sociocultural factors. ${ }^{19}$

This study assesses drug use patterns and psychiatric symptoms of anxiety and depression among young Brazilian sexual minority ecstasy and LSD users and compares findings with those obtained for their heterosexual peers.

\section{Methods}

\section{Participants and methods}

The present data were drawn from a larger observational study that recruited and enrolled 240 club-goers in Porto Alegre, a state capital and large metropolitan area in southern Brazil. Participants were recruited from March to July 2010 using targeted sampling and ethnographic mapping. Eligibility criteria were: a) reported use of ecstasy, LSD or both at least once within the past 90 days; and b) no current drug or alcohol treatment.

The project staff and key informants in the club scene mapped the main nightclubs and rave parties where potential participants were known to gather. Potential participants were approached and invited to participate in the study. Face-to-face interviews that lasted about 15 minutes were conducted in loco to assess inclusion criteria. Those who met all criteria were invited to participate in a more detailed interview and other data collection procedures. Field interviewers were trained to collect data, with particular emphasis on elements of rapport, street terminology of drug use, and confidentiality and privacy of the information obtained. To ensure the quality of the data collected, the staff was trained to avoid interviewing visibly intoxicated individuals, due to concerns about both data validity and capacity to consent. All interview data were recorded using brief paper and pencil questionnaires.

After providing written informed consent, the participants were interviewed using an adapted version of the Global Appraisal of Individual Needs (GAIN-I) instrument (http://gaincc.org/GAINI). ${ }^{20}$ At the end of the interview, they received a lunch voucher (US\$20) as a compensation for their participation.

The study was approved by the University of Delaware Institutional Review Board and by the Institutional Review Board and Research Ethics Committee of Hospital de Clínicas de Porto Alegre (CAEE no. 22864113.6.0000.5327).

\section{Instrument}

A brief screening form based on studies conducted in the U.S. with similar populations ${ }^{21,22}$ was developed to identify eligible participants. The instrument used for subsequent primary data collection from selected individuals was an abbreviated version of GAIN-I, developed for brief intercept interviewing in street locations and adapted to the Brazilian context. ${ }^{20}$ 
The GAIN-I was validated and has been used to interview both adolescents and adults in a variety of settings, including synthetic drug users. ${ }^{21}$ GAIN-I results have provided the main clinical and research measures in many National Institute on Drug Abuse (NIDA)-funded multicenter studies. The original version of the instrument has eight sections: demographic characteristics; information regarding substance use patterns; physical health; risk behaviors; mental health; environment; legal; and vocational. The adapted version used in the present study was shortened since it was to be used for brief intercept interviewing in street locations. The following sections were kept in the final shortened format and adapted to the Brazilian context: 1) substance use; 2) mental health; 3) risk behaviors; and 4) vocational. Questions related to basic demographic information included age, gender, education (years of schooling), and monthly individual income. Substance use was assessed by asking participants how many times a particular substance was used in the 90 days before the interview, as well as during their lifetime. A comprehensive list of illicit drugs and their correspondent "street names" was presented to participants and included: alcohol, cannabis, inhalants, ecstasy, LSD, methamphetamine, and cocaine.

Mental health data collection focused on the 12 months preceding the interview, and symptoms were classified according to the Diagnostic and Statistical Manual of Mental Disorders, 4th edition (DSM-IV). The mental health section included three subscales: Anxiety and Fear Symptoms Scale (AFSS), Depression Symptoms Scale (DSS) and Traumatic Symptoms Scale (TSS). Anxiety symptoms were assessed using the 12 items of the AFSS (e.g., "During the past 12 months, have you had significant problems feeling very anxious, nervous, tense, scared, panicked or like something bad was going to happen?"). Depressive symptoms were assessed using the 11 items of the DSS (e.g., "During the past 12 months, have you had significant problems with feeling very trapped, lonely, sad, blue, depressed, or hopeless about the future?"). Traumatic symptoms were assessed using the 12 items of the TSS (e.g., "When something reminds you of the past, do you become very distressed and upset?"). In the present study, only the data collected using DSS and AFSS are presented; TSS data are still undergoing analysis and will be the subject of future publications. All variables in the psychiatric symptom scales were dichotomous (yes/no questions).

\section{Data analysis}

Categorical variables were presented as absolute and relative frequencies, and interval variables, as means and standard deviation or as medians and interquartile range (first and third quartiles). Psychiatric symptoms were classified, based on the number of symptoms reported in the 12 months before the interview, as mild, moderate, or clinically relevant. For anxiety, categories were: mild, 0-1 symptom; moderate, 2-6 symptoms; and clinically relevant, 7-12 symptoms. For depression, categories were: mild, 0-1 symptom; moderate, 2-5 symptoms; and clinically relevant, 6 or more symptoms.

For the purpose of logistic regression, the three categories of psychiatric symptoms (mild, moderate and clinically relevant) were treated as yes/no variables, i.e., the moderate and clinically relevant categories were considered as yes, and the mild category was considered as no.

Data about drug use in the last 90 days were described as medians and interquartile ranges. The Mann-Whitney test was used for the comparison of the drug distribution profile in the two groups (heterosexual and sexual minority club goers). The level of significance was set at $p<0.05$.

Univariate Poisson regression was used to identify independent variables significantly associated with the study outcome. Variables with $p<0.10$ in the univariate model were considered eligible to enter the multivariate analysis. Collinearity diagnostics were analyzed between the adjustment variables. The variable age of inhalant use $(p=0.085)$ was not included as an adjustment variable because 118 participants out of 240 reported inhalant use. Heterosexual participants were used as reference group for subsequent analyses. All analyses were adjusted for gender, education, age, lifetime cocaine use, and mean number of days of any drug use in the past 90 days.

Demographic characteristics, psychiatric symptoms of depression and anxiety over the past 12 months, substance use patterns over the past 90 days, and lifetime substance use were compared between sexual minority and heterosexual participants. Sexual minority participants were defined as those who reported their sexual orientation as gay, lesbian or bisexual in response to the item: "Which of the following best describes you?" The possible answers were (1) heterosexual or straight, (2) gay or lesbian, or (3) bisexual.

\section{Results}

\section{Demographic characteristics}

Of the 240 subjects enrolled (mean age: $22.9 \pm 4.5$ ), $57.9 \%$ were men; $69 \%$ had between 5 and 8 years of schooling; $42.1 \%$ were employed; and $60 \%$ had a mean monthly income of up to US\$ 602.80 , about three times the monthly minimum wage in Brazil at the time 
of the study. The number of heterosexual participants $(n=171,71.3 \%)$ was higher than the number of those reporting sexual minority orientation ( $n=69,28.7 \%$; gay or lesbian, $17 \%$; bisexual, $11.7 \%$ ). The characteristics of this subset of participants are described below.

The sexual minority group comprised 69 participants $(28.7 \%)$, whose mean age was $22.7 \pm 4.95$ years old; $49.3 \%$ were men. The comparison of heterosexuals and sexual minority participants revealed no statistical differences in terms of demographic characteristics. Most non-heterosexual participants were studying, working, or both at the time of the interview (95.6\%); $56.5 \%$ had a mean individual monthly income of up to US\$ 602.08 ; and $76.5 \%$ had between 5 and 8 years of schooling (Table 1).

\section{Drug use}

Lifetime prevalence of drug use in the overall sample $(\mathrm{N}=240)$ was highest for alcohol $(99.6 \%)$ and cannabis $(95.4 \%)$, followed by LSD $(88.3 \%)$ and ecstasy $(83.2 \%) ; 33.3 \%$ reported to have used both ecstasy and LSD on the same occasion. In addition, $56.3 \%$ reported the use of inhalants, and $23.2 \%$, of amphetamines. The median number of days of use of any drug in the 90 days before the interview was 21 days (interquartile range: 12.56 to 32.37). Lifetime cocaine use was reported by over half of the participants $(55 \%)$, and $44 \%$ of these used cocaine in the 90 days before the interview.

In the sexual minority group, $98.6 \%$ used alcohol in the 90 days before the interview; also, $95.7 \%$ reported lifetime cannabis use, and $77.3 \%$ of these used it in the 90 days before the interview. The analysis of recent use (90 days) revealed that $79.4 \%$ used ecstasy, $84.7 \%$ LSD, and $48.9 \%$ cocaine. Lifetime cocaine use $(p=0.007)$ was significantly different between the groups (Table 2).

\section{Psychiatric symptoms}

Univariate Poisson regression was used to determine which variables were independently associated with the primary outcome. The following anxiety and depression variables reaching $p<0.10$ were included in the multivariate model: (1) "feeling very anxious, nervous, tense, scared, panicked or like something

Table 1 - Sample characteristics

\begin{tabular}{|c|c|c|c|c|}
\hline \multirow[b]{2}{*}{ Variables } & \multirow{2}{*}{$\begin{array}{c}\text { Total, n (\%) } \\
\mathbf{N}=240\end{array}$} & \multicolumn{2}{|c|}{ Homosexual/bisexual, n (\%) } & \multirow[b]{2}{*}{ p } \\
\hline & & Yes $(n=69)$ & No $(n=171)$ & \\
\hline Age, mean \pm standard deviation & $22.99 \pm 4.54$ & $22.70 \pm 4.95$ & $23.10 \pm 4.38$ & 0.545 \\
\hline Gender, n (\%) & & & & 0.115 \\
\hline Female & $101(42.1)$ & $35(50.7)$ & $66(38.6)$ & \\
\hline Male & 139 (57.9) & $34(49.3)$ & $105(61.4)$ & \\
\hline Income, $\mathrm{n}(\%)$ & & & & 0.828 \\
\hline No income & $42(17.5)$ & $13(18.8)$ & $29(17.0)$ & \\
\hline Up to US\$ 602.80* & $143(59.6)$ & $39(56.5)$ & $104(60.8)$ & \\
\hline More than US\$ 602.80 & $55(22.9)$ & $17(24.6)$ & $38(22.2)$ & \\
\hline Occupation, n (\%) & & & & 0.885 \\
\hline Studying and working & $48(20)$ & $14(20.3)$ & 34 (19.9) & \\
\hline Student & $76(31.7)$ & $23(33.3)$ & $53(31.0)$ & \\
\hline Employed & $101(42.1)$ & $29(42.0)$ & $72(42.1)$ & \\
\hline No study/no work & $15(6.3)$ & $3(4.3)$ & $12(7.0)$ & \\
\hline Education level (years of schooling), $n(\%)$ & & & & 0.277 \\
\hline$>8$ & $58(24.3)$ & $12(17.6)$ & $46(26.9)$ & \\
\hline $5-8$ & $165(69.0)$ & $52(76.5)$ & $113(66.1)$ & \\
\hline $1-4$ & $16(6.7)$ & $4(5.9)$ & $12(7.0)$ & \\
\hline \multicolumn{5}{|l|}{ Sexual orientation, n (\%) } \\
\hline Bisexual & $28(11.7)$ & & & \\
\hline Homosexual & $41(17.0)$ & & & \\
\hline Heterosexual & $171(71.3)$ & & & \\
\hline
\end{tabular}

Heterosexual participants were used as the reference category.

* US $\$ 1=\mathrm{R} \$ 1.63$ at the time of the study. 
Table 2 - Drug use patterns

\begin{tabular}{|c|c|c|c|c|}
\hline \multirow[b]{2}{*}{ Variables } & \multirow{2}{*}{$\begin{array}{c}\text { Total, n (\%) } \\
\text { N=240 }\end{array}$} & \multicolumn{2}{|c|}{ Homosexual/bisexual, n (\%) } & \multirow[b]{2}{*}{$\mathbf{p}$} \\
\hline & & Yes $(n=69)$ & No $(n=171)$ & \\
\hline Days of drug use* & $21.41[12.6-32.4]$ & $24.3[12.6-32.9]$ & $21.12[12.6-31.7]$ & 0.711 \\
\hline Alcohol $^{+}$ & $239(99.6)$ & $69(100.0)$ & $169(99.4)$ & $>0.999$ \\
\hline Age at onset of use* & $14[13-15]$ & $13[12-15]$ & $14[13-15]$ & 0.775 \\
\hline Last use & & & & 0.676 \\
\hline More than 90 days & $6(2.5)$ & $1(1.4)$ & $5(2.9)$ & \\
\hline Within 90 days & $233(97.5)$ & $68(98.6)$ & $165(97.1)$ & \\
\hline Days of use within 90 days* & $30[16.3-50]$ & $36[23-50]$ & $30[15-50]$ & 0.055 \\
\hline Cannabis $^{+}$ & $227(95.4)$ & $66(95.7)$ & $161(95.3)$ & $>0.999$ \\
\hline Age at onset of use* & $15[14-17]$ & $15[14-17]$ & $15[14-17]$ & 0.781 \\
\hline Last use & & & & $>0.999$ \\
\hline More than 90 days & $53(23.1)$ & $15(2.7)$ & $38(23.3)$ & \\
\hline Within 90 days & $174(76)$ & $51(77.3)$ & $123(75.5)$ & \\
\hline Days of use within 90 days* & $36[10-88]$ & $32[3.5-88]$ & $36[10-88]$ & 0.633 \\
\hline Inhalants $^{+}$ & $134(56.3)$ & $44(63.8)$ & $90(53.3)$ & 0.180 \\
\hline Age at onset of use* & $16[15-20]$ & $17[16-18]$ & $16[15-22]$ & 0.085 \\
\hline Last use & & & & 0.552 \\
\hline More than 90 days & $88(56.8)$ & $26(56.5)$ & $62(56.9)$ & \\
\hline Within 90 days & $44(28.4)$ & $16(34.8)$ & $28(25.7)$ & \\
\hline Days of use within 90 days* & $3[1.0-10]$ & $3[1.5-22.5]$ & $2.5[1-7.8]$ & 0.527 \\
\hline Ecstasy $^{+}$ & $198(83.2)$ & $62(89.9)$ & $136(80.5)$ & 0.118 \\
\hline Age at onset of use* & $18[17-22]$ & $18[17-20]$ & $18.5[17-22]$ & 0.220 \\
\hline Last use & & & & 0.235 \\
\hline More than 90 days & $51(25.1)$ & $12(19)$ & $39(27.9)$ & \\
\hline Within 90 days & $148(72.9)$ & $50(79.4)$ & $98(70)$ & \\
\hline Days of use within 90 days* & $2[1-6]$ & $2[1-9]$ & $2[1-6]$ & $>0.999$ \\
\hline $\mathrm{LSD}^{+}$ & $211(88.3)$ & $57(82.6)$ & $154(90.6)$ & 0.129 \\
\hline Age at onset of use* & $19[17-21]$ & $18[17-20]$ & $19[17-21.75]$ & 0.181 \\
\hline Last use & & & & 0.702 \\
\hline More than 90 days & $31(14.3)$ & $7(11.9)$ & $24(15.20)$ & \\
\hline Within 90 days & $180(82.9)$ & $50(84.7)$ & $130(82.3)$ & \\
\hline Days of use within 90 days* & $2.5[1-5]$ & $3[1-10]$ & $2[1-5]$ & 0.153 \\
\hline Methamphetamine $^{+}$ & $56(23.5)$ & $17(25.0)$ & $39(22.9)$ & 0.866 \\
\hline Age at onset of use* & $19[17-21]$ & $18[17-21.5]$ & $19[17-21]$ & 0.951 \\
\hline Last use & & & & 0.578 \\
\hline More than 90 days & $24(26.4)$ & $9(29)$ & $15(25)$ & \\
\hline Within 90 days & $30(33.0)$ & $8(25.8)$ & $22(36.7)$ & \\
\hline Days of use within 90 days & $2.5[1-5.3]$ & $3[1-6]$ & $2[1-5]$ & 0.743 \\
\hline Cocaine $^{+}$ & $132(55.2)$ & $48(69.6)$ & $84(49.4)$ & $0.007^{\ddagger}$ \\
\hline Age at onset of use* & $18[16-21]$ & $18[16-20]$ & $18[15-21]$ & 0.392 \\
\hline Last use & & & & 0.546 \\
\hline More than 90 days & $56(37.6)$ & $16(34)$ & $40(39.2)$ & \\
\hline Within 90 days & $65(43.6)$ & $23(48.9)$ & $42(41.2)$ & \\
\hline Days of use within 90 days* & $6.5[3-24]$ & $11[4.3-46.5]$ & $4.5[2-18.8]$ & 0.055 \\
\hline
\end{tabular}

* Age at onset of use and days of use within 90 days presented as median [interquartile range]; p-value for drug distribution profile in the two groups (MannWhitney test).

${ }^{+}$Lifetime use.

* Significant result. 
bad was going to happen" ( $p=0.067)$; (2) "repeating an action over and over, or having thoughts that kept running over your mind" $(p=0.004) ;(3)$ "problems with remembering, concentrating, making decisions, or having your mind go blank" $(p=0.092)$; and (4) "getting into a lot of arguments and feeling the urge to shout, throw things, beat, injure and harm someone" $(p=0.082)$. Of the variables included in the multivariate final model, "repeating an action over and over, or having thoughts that kept running over your mind" showed a higher prevalence in the sexual minority group than in the heterosexual group (prevalence ratio $[P R]=1.703 ; 95 \%$ confidence interval $[95 \% C I] 1.06-$ 2.73; $\mathrm{p}=0.028)$.

Table 3 shows PRs (and respective 95\%CIs) obtained at the univariate and multivariate Poisson models (univariate: anxiety or depression symptoms; multivariate: anxiety and depression symptoms). The prevalence of depression symptoms was 37\% higher in the non-heterosexual than in the heterosexual group $(P R=1.79 ; 95 \%$ CI 1.03-3.11; $p=0.037) .^{23}$

\section{Discussion}

To the authors' knowledge, this is the first study to assess drug use patterns and psychiatric symptoms of anxiety and depression among young Brazilian sexual minority ecstasy and LSD users and to compare findings with those obtained for their heterosexual peers. Self-reported identification as non-heterosexual was associated with a high prevalence of depression symptoms in the past 12 months, ${ }^{16,24,25}$ as well as with an anxiety manifestation of "repeating an action over and over, or having thoughts that kept running over your mind" (PR=1.703; 95\%CI 1.06-2.73; $p=0.028)$.
A previous study conducted by Chakraborty et al. ${ }^{9}$ also found a high prevalence of depressive and anxiety symptoms in sexual minority individuals when compared with the heterosexual population. Other studies assessing mental health status among nonheterosexuals revealed that anxiety, depression and relationship issues are the most frequent complaints at consultations in the public mental health system.7,26,27 This suggests that the perceived discrimination faced by sexual minority subgroups acts as a social stressor in mental health problems. ${ }^{20,28}$ Our non-heterosexual participants reported more depressive symptoms over the past 12 months and showed a significantly higher result for compulsive behaviors and intrusive thoughts. In this regard, the multifactorial etiology of this result may be understood as one of the consequences of increased societal prejudice, stigma and discrimination to which this group is subjected. Diaz et al. ${ }^{29}$ studied a sample of Latino non-heterosexual men living in the United States and also found a high prevalence of depression. Particularly, in Latino non-heterosexual communities, prejudice and social stigma are driven by sociocultural factors, e.g., social disadvantage and expressive style. The lack of openness about sexual orientation may also explain the association between stigma, drug use and psychiatric symptoms. ${ }^{30}$ In our study, the comparison between groups revealed that anxiety and depression were more strongly present in the non-heterosexual group, even though anxiety is one of the most prevalent disorders in the general population. The association between symptoms of anxiety and depression may have affected the analyses, and therefore may have been a confounding factor.

Clinically, anxiety and depression are often associated with the use of alcohol and drugs as a meaning of self-medication ${ }^{31}$ and as a relief for

Table 3 - Multivariate regression analysis of anxiety and depression symptoms according to sexual orientation

\begin{tabular}{|c|c|c|c|c|c|c|c|c|c|}
\hline \multirow[b]{2}{*}{ Variables } & \multirow{2}{*}{$\begin{array}{l}\text { Total, } \mathbf{n} \\
\mathbf{N}=\mathbf{2 4 0}\end{array}$} & \multicolumn{2}{|c|}{$\begin{array}{c}\text { Homosexual/bisexual, } \\
\text { n (\%) }\end{array}$} & \multicolumn{3}{|c|}{$\begin{array}{l}\text { Univariate anxiety or } \\
\text { depression symptoms }\end{array}$} & \multicolumn{3}{|c|}{$\begin{array}{l}\text { Multivariate anxiety and } \\
\text { depression symptoms }\end{array}$} \\
\hline & & Yes $(n=69)$ & No $(n=171)$ & PR & $95 \% \mathrm{CI}$ & $\mathbf{p}$ & PR & $95 \% \mathrm{CI}$ & $\mathbf{p}$ \\
\hline \multicolumn{10}{|l|}{ Anxiety } \\
\hline Yes* & 159 & $49(71.0)$ & $110(64.3)$ & 1.13 & $0.71-1.79$ & 0.604 & 0.84 & $0.50-1.41$ & 0.511 \\
\hline No & 81 & $20(29.0)$ & $61(35.7)$ & 1 & & & 1 & & \\
\hline \multicolumn{10}{|l|}{ Depression } \\
\hline Yes* & 164 & $54(78.3)$ & $110(64.3)$ & 1.64 & $0.99-2.71$ & 0.053 & 1.79 & $1.03-3.11$ & 0.037 \\
\hline No & 76 & $15(21.7)$ & $61(35.7)$ & 1 & & & 1 & & \\
\hline
\end{tabular}

$95 \% \mathrm{CI}=95 \%$ confidence interval; PR = prevalence ratio.

Univariate = composite model of having anxiety or depression symptoms, adjusted for lifetime cocaine use, gender, education, age, and mean number of days of drug use within 90 days.

Multivariate $=$ composite model of having anxiety and depression symptoms adjusted for lifetime cocaine use, gender, education, age, and mean number of days of drug use within 90 days.

* Presence of any anxiety/depressive symptom in the 12 months prior to the interview. 
negative emotions. The desire to escape or avoid negative emotions ${ }^{30,32}$ has been found to be one of the psychological factors associated with drug use among non-heterosexual populations in general. In our study, sexual minority was suspected to be a risk factor for substance use; however, surprisingly, our study found similar rates of substance use (except for cocaine), age at onset of use, and number of days of drug use among heterosexual and sexual minority participants. Conversely, non-heterosexual individuals showed a higher prevalence of lifetime and recent use of cocaine than heterosexual participants. These findings are consistent with those reported by Newcomb et al. ${ }^{33}$ : in that study, the prevalence of polysubstance use both in lifetime (64.4\%) and in the past 6 months (53.0\%) was higher among non-heterosexual individuals compared with heterosexual participants; conversely, a minority reported never having used any substances in their lifetime $(12.9 \%)$ or in the past 6 months $(17.6 \%)$.

The high prevalence of cocaine use among nonheterosexuals may be connected with sexual drive and with a predisposition to psychiatric comorbidities, as a way to temporarily move away from circumstances and factors that favor emotional stress. According to other studies, despite the predisposition to drug use in this population, drug use patterns differ over time and depend on geographical region, ${ }^{33}$ but little is currently known about differences in non-heterosexual subgroups across multiple substances, which limits our understanding of this phenomenon. Obtaining such information could help identify more susceptible regions, types of substances used, and use patterns to be targeted in prevention programs. Studies have often focused on the prevalence or frequency of use of a single substance, class of drugs, or composite measures, ${ }^{20,26}$ which limits the possibility of comparing prevalence rates of use of multiple substances.

Some limitations of the present study should be considered. One important limitation for the comparability of our data - which is also strength of the study - is the lack of previous similar studies conducted either in Brazil or elsewhere in the world. Also, individuals were selected using convenience sampling; therefore, our sample may not be representative of the sexual minority club-going population subgroup. Nonetheless, the consistency between our findings and those reported in the relevant literature suggests at least some degree of similarity between our sample and other non-heterosexual drug-using populations. Data collected at nightclubs, parties and festivals are known to be a good source for prevalence studies. ${ }^{34-37}$ However, sample size and data collection site may affect result generalizability. For instance, the choice of collection site may result in a bias toward including individuals under the effect of alcohol or other substances, which may compromise data validity. However, our staff was trained to avoid interviewing visibly intoxicated individuals precisely due to concerns about both data validity and capacity to consent.

In conclusion, our findings suggest that strategies should be developed to assess and address individual needs and to motivate sexual minority people to seek treatment. In addition, the results show that substance use in this population is potentially more severe than in the heterosexual population, as demonstrated by the higher rates of drug use and number of days of drug use.

Several types of treatment, such as medication, psychotherapy, gay counseling and self-help websites, are available for this population. Approaches that take into consideration cultural differences and minority groups should be implemented to prevent and treat drug use. Social isolation and drug use, as a cause or consequence of depression and anxiety, may worsen the course of the disease. Furthermore, sexual minorities need to be taught strategies to cope with prejudice, and public health services should be able to provide family and community support when these individuals are victimized.

\section{Acknowledgements}

This study was supported by the Fogarty International Center (grant 1R03TW007612) and by Fundo de Incentivo à Pesquisa e Eventos - Hospital de Clínicas de Porto Alegre (FIPE-HCPA), Brazil (GPPG-HCPA 07-391). The authors thank the study participants for their contribution to this research, as well as current and past investigators and staff. We would specifically like to thank Sinara Santos, Fernanda Cubas de Paula, Gabriela Moraes, Camila Bitencourt, Bruno Rech, Madson Gomes, and Rodrigo Sibemberg for their support.

\section{Disclosure}

No conflicts of interest declared concerning the publication of this article.

\section{References}

1. Cochran SD, Mays VM, Sullivan JG. Prevalence of mental disorders, psychological distress, and mental health services use among lesbian, gay, and bisexual adults in the United States. J Consult Clin Psychol. 2003;71:53-61. 
2. Busseri MA, Willoughby $T$, Chalmers $H$, Bogaert AF. On the association between sexual attraction and adolescent risk behavior involvement: Examining mediation and moderation. Dev Psychol. 2008;44:69-80.

3. Conron KJ, Mimiaga MJ, Landers SJ. A population-based study of sexual orientation identity and gender differences in adult health. Am J Public Health. 2010;100:1953-60.

4. Cochran SD, Mays VM. Burden of psychiatric morbidity among lesbian, gay, and bisexual individuals in the California Quality of Life Survey. J Abnorm Psychol. 2009;118:647-58.

5. Lipsky S, Krupski A, Roy-Byrne P, Huber A, Lucenko BA, Mancuso D. Impact of sexual orientation and co-occurring disorders on chemical dependency treatment outcomes. J Stud Alcohol Drugs. 2012;73:401-12.

6. Austin SB, Ziyadeh N, Fisher LB, Kahn JA, Colditz GA, Frazier AL. Sexual orientation and tobacco use in a cohort study of US adolescent girls and boys. Arch Pediatr Adolesc Med. 2004; 158:317-22.

7. Cochran SD, Mays V, Corliss H, Smith TW, Turner J. Self-reported altruistic and reciprocal behaviors among homosexually and heterosexually experienced adults: implications for HIV/AIDS service organizations. AIDS Care. 2009;21:675-82.

8. Grant BF, Stinson FS, Dawson DA, Chou SP, Dufour MC, Compton $W$, et al. Prevalence and co-occurrence of substance use disorders and independent mood and anxiety disorders: results from the National Epidemiologic Survey on Alcohol and Related Conditions (NESARC). Arch Gen Psychiatry. 2004;61:807-16.

9. Chakraborty A, McManus S, Brugha TS, Bebbington P, King M. Mental health of the non-heterosexual population of England. $\mathrm{Br}$ ] Psychiatry. 2011;198:143-8.

10. Hatzenbuehler ML, Keyes KM, Narrow WE, Grant BF, Hasin DS. Racial/ethnic disparities in service utilization for individuals with co-occurring mental health and substance use disorders in the general population: results from the national epidemiologic survey on alcohol and related conditions. J Clin Psychiatry. 2008;69:1112-21.

11. Marshall BD, Socías ME, Kerr T, Zalazar V, Sued O, Arístegui I. Prevalence and correlates of lifetime suicide attempts among transgender persons in Argentina. J Homosex. 2016;63:955-67.

12. Cochran SD, Mays VM. Relation between psychiatric syndromes and behaviorally defined sexual orientation in a sample of the US population. Am J Epidemiol. 2000;151:516-23.

13. Cochran SD, Mays VM. Lifetime prevalence of suicidal symptoms and affective disorders among men reporting same-sex sexual partners: results from the NHANES III. Am J Public Health. 2000;90:573-8.

14. Cochran SD, Keenan C, Schober C, Mays VM. Estimates of alcohol use and clinical treatment needs among homosexually active men and women in the US population. J Consult Clin Psychol. 2000;68:1062-71.

15. Gilman SE, Cochran SD, Mays VM, Hughes M, Ostrow D, Kessler RC. Risk of psychiatric disorders among individuals reporting same-sex sexual partners in the National Comorbidity Survey. Am J Public Health. 2001;91:933-9.

16. King M, Semlyen J, Tai SS, Killaspy H, Osborn D, Popelyuk D, et al. A systematic review of mental disorder, suicide, and deliberate self harm in lesbian, gay and bisexual people. BMC Psychiatry. 2008;8:70.

17. Warner J, McKeown E, Griffin M, Johnson K, Ramsay A, Cort C, et al. Rates and predictors of mental illness in gay men, lesbians and bisexual men and women: results from a survey based in England and Wales. Br J Psychiatry. 2004;185:479-85.

18. Roxburgh A, Lea T, de Wit J, Degenhardt L. Sexual identity and prevalence of alcohol and other drug use among Australians in the general population. Int J Drug Policy. 2016;28:76-82.

19. Cochran SD, Mays VM, Alegria M, Ortega AN, Takeuchi D. Mental health and substance use disorders among Latino and Asian American lesbian, gay, and bisexual adults. J Consult Clin Psychol. 2007;75:785-94.

20. Traube DE, Schrager SM, Holloway IW, Weiss G, Kipke MD. Environmental risk, social cognition, and drug use among young men who have sex with men: longitudinal effects of minority status on health processes and outcomes. Drug Alcohol Depend. 2013;127:1-7.

21. Ibanez GE, Kurtz SP, Surratt HL, Inciardi JA. Correlates of heterosexual anal intercourse among substance-using clubgoers. Arch Sex Behav. 2010;39:959-67.

22. Inciardi $J A$, Surratt $H L$, Kurtz SP, Cicero TJ. Mechanisms of prescription drug diversion among drug-involved club- and streetbased populations. Pain Med. 2007;8:171-83.

23. Barros AJ, Hirakata VN. Alternatives for logistic regression in cross-sectional studies: an empirical comparison of models that directly estimate the prevalence ratio. BMC Med Res Methodol. 2003;3:21.

24. Marshal MP, Dietz LJ, Friedman MS, Stall R, Smith HA, McGinley $J$, et al. Suicidality and depression disparities between sexual minority and heterosexual youth: a meta-analytic review. J Adolesc Health. 2011;49:115-23.

25. Institute of Medicine (US) Committee on Lesbian G, Bisexual, and Transgender Health Issues and Research Gaps and Opportunities. The health of lesbian, gay, bisexual, and transgender people: building a foundation for better understanding. Washington: National Academies Press; 2011.

26. Wong CF, Weiss G, Ayala G, Kipke MD. Harassment, discrimination, violence, and illicit drug use among young men who have sex with men. AIDS Educ Prev. 2010;22:286-98.

27. Goldberg AE, Smith JZ. Stigma, social context, and mental health: lesbian and gay couples across the transition to adoptive parenthood. J Couns Psychol. 2011;58:139-50.

28. Tucker JS, Ellickson PL, Klein DJ. Understanding differences in substance use among bisexual and heterosexual young women. Womens Health Issues. 2008;18:387-98.

29. Diaz RM, Ayala G, Bein E, Henne J, Marin BV. The impact of homophobia, poverty, and racism on the mental health of gay and bisexual Latino men: findings from 3 US cities. Am J Public Health. 2001;91:927-32.

30. Herek GM, Gillis JR, Ogan JC. Internalized stigma among sexua minority adults: insights from a social psychological perspective. J Couns Psychol. 2009;56:32-43.

31. Lea T, Reynolds R, de Wit J. Alcohol and other drug use, club drug dependence and treatment seeking among lesbian, gay and bisexual young people in Sydney. Drug Alcohol Rev. 2013;32:303-11.

32. Carrico AW, Pollack LM, Stall RD, Shade SB, Neilands TB, Rice TM, et al. Psychological processes and stimulant use among men who have sex with men. Drug Alcohol Depend. 2012;123:79-83.

33. Newcomb ME, Ryan DT, Greene GJ, Garofalo R, Mustanski B. Prevalence and patterns of smoking, alcohol use, and illicit drug use in young men who have sex with men. Drug Alcohol Depend. 2014; $141: 65-71$.

34. Measham F, Moore K. Repertoires of distinction: exploring patterns of weekend polydrug use within local leisure scenes across the English night time economy. Criminol Crim Justice. 2009;9:437-64.

35. Measham F, Wood DM, Dargan PI, Moore K. The rise in legal highs: prevalence and patterns in the use of illegal drugs and first- and second-generation "legal highs" in South London gay dance clubs. J Subs Use. 2011;16:263-72.

36. Measham F, Moore K, Østergaard J. Mephedrone, "Bubble" and unidentified white powders: the contested identities of synthetic "legal highs". Drugs Alcohol Today. 2011;3:137-46.

37. Wood DM, Measham F, Dargan PI. Our favourite drug: prevalence of use and preference for mephedrone in the London night-time economy 1 year after control. J Subs Use. 2012;68:853-6.

\section{Correspondence:}

Lysa Silveira Remy

Rua Prof. Álvaro Alvim, 400

90420-020 - Porto Alegre, RS - Brazil

Tel./Fax: +55 (51) 3359.6472

E-mail: lysaremy@gmail.com 